\title{
KARAKTERISASI DAN IDENTIFIKASI METABOLIT SEKUNDER ISOLAT JAMUR ENDOFIT DAUN SUKUN (ARTOCARPUS ALTILIS)
}

\author{
Eko Nur Setiawan, Nur Mita, Arsyik Ibrahim \\ Laboratorium Penelitian dan Pengembangan FARMAKA TROPIS, Fakultas Farmasi, \\ Universitas Mulawarman, Samarinda, Kalimantan Timur \\ Email : ecqho.1611@gmail.com
}

\begin{abstract}
ABSTRAK
Telah dilakukan penelitian "Karakterisasi dan Identifiksi Metabolit Sekunder Isolat Jamur Endofit Daun Sukun (Artocarpus Altilis)". Tujuan dari penelitian ini adalah untuk mengetahui karakterisasi isolat jamur endofit yang diisolasi dari daun sukun dan golongan metabolit sekunder yang dimiliki oleh isolat jamur endofit tersebut. Karakterisasi isolat jamur endofit dilakukan secara makroskopis dan mikroskopis. Untuk identifikasi metabolit sekunder isolat jamur endofit dilakukan dengan uji reaksi kimia dan metode KLT (Kromatografi Lapis Tipis) dengan pereaksi semprot spesifik. Hasil penelitian menunjukkan adanya dua isolat jamur endofit ( $\operatorname{IFE}_{1} \mathrm{P}$ dan $\left.\mathrm{IFE}_{2} \mathrm{HK}\right)$ dari daun sukun. Hasil karakterisasi secara makroskopis menunjukkan, bahwa pada isolat $\mathrm{IFE}_{1} \mathrm{P}$ memiliki koloni berwarna putih dengan tekstur granular, permukaan berbentuk konsentris dan elevasi halus serta bentuk penonjolan timbul. Secara mikroskopis isolat $\operatorname{IFE}_{1} \mathrm{P}$ memiliki hifa aseptat dengan hialin, konidia dan konidiofor. Pengamatan secara makroskopis menunjukan, bahwa pada isolat $\mathrm{IFE}_{2} \mathrm{HK}$ memiliki koloni berwarna hijau kehitaman dengan tekstur menyerupai beludru, berbentuk bulat dengan tepi bergelombang dan elevasi halus dengan penonjolan berbentuk bukit. Secara mikroskopis isolat $\mathrm{IFE}_{2} \mathrm{HK}$ memiliki hifa septat berbentuk rhizoid dan terdapat konidiospora. Kedua isolat jamur endofit memiliki metabolit sekunder yang hampir serupa seperti tanaman inangnya, yaitu flavonoid, polifenol, triterpen, dan steroid. Senyawa saponin hanya terdapat pada isolat $\operatorname{IFE}_{1} \mathrm{P}$ dan tidak teridentifikasi pada isolat $\mathrm{IFE}_{2} \mathrm{HK}$.
\end{abstract}

Kata kunci : Jamur endofit, Artocarpus altilis, Metabolit sekunder, KLT (Kromatografi Lapis Tipis)

\begin{abstract}
A research about "The Characterization and Identification of Secondary Metabolites from Endophytic Fungi Isolates of Breadfruit Leaves (Artocarpus altilis)" have been conducted. The research was aimed to determine the characterization of endophytic fungi isolates have been isolasted from breadfruit leaves and determine secondary metabolites from the isolates. Endophytic fungi isolates was characterized by macroscopic and microscopic test. And secondary metabolites was identified by tubes test and TLC (Thin Layer Chromatography) with the specific spray reagents. The results of this research showed that two endophytic fungi isolates ( $I F E_{1} P$ and $I F E_{2} H K$ ) have been obtained from Breadfruit Leaves. The results of macroscopic characterization showed that IFE ${ }_{1} P$ has white colony with granulose texture, concentric surface, and smooth elevate appear to the surface. Microscopic characterization showed that IFE ${ }_{1} P$ has hifa aseptat, konidia, and konidiofor. The results of macroscopic characterization showed that IFE ${ }_{2} H K$ has dark
\end{abstract}


green colony with velvety texture, waveform on radial curve surface, and smooth elevate. Microscopic characterization showed that $\mathrm{IFE}_{2} \mathrm{HK}$ has hifa septat with rhizoid forming and konidiospores. Both of the isolates (IFE $P$ and $I F E_{2} H K$ ) have a similar secondary metabolites such as flavonoids, polyphenols, triterpenes and steroids same as its host plants. Saponins was obtained in IFE1P, but wasn't showed on IFE ${ }_{2} H K$.

Key words : Endophytic fungi, Artocarpus altilis, Secondary metabolites, TLC (Thin Layer Chromatography)

\section{PENDAHULUAN}

Berbagai jenis senyawa bioaktif dengan beragam fungsi yang terkandung dalam tumbuhan maupun tanaman, diduga dapat dihasilkan oleh jamur endofit (Radji, 2005). Diungkapkan oleh Strobel dkk. (2003) bahwa kemampuan jamur endofit memproduksi senyawa metabolit sekunder sesuai dengan tanaman inangnya, merupakan peluang yang sangat besar dan dapat diandalkan untuk memproduksi metabolit sekunder dari jamur endofit yang diisolasi dari tanaman inangnya tersebut.

Jamur endofit adalah jamur yang hidup di dalam jaringan tanaman pada periode tertentu dan mampu hidup dengan membentuk koloni dalam jaringan tanaman tanpa membahayakan inangnya (Tan, 2001). Menurut Tombe (2008), jamur endofit terdapat di dalam sistem jaringan tanaman, seperti daun, bunga, ranting ataupun akar. Senyawa yang dihasilkan oleh jamur endofit dapat berupa senyawa anti kanker, antivirus, antibakteri, antifungi, hormon pertumbuhan tanaman, insektisida dan lain-lain (Strobel, 2004).

Salah satu tanaman obat yang berpotensi untuk kesehatan, yaitu tanaman sukun (Artocarpus altilis) yang telah banyak digunakan dan dilaporkan memiliki banyak kegunaan. Daun dari tanaman ini, mengandung senyawa berkhasiat seperti saponin, polifenol, tanin, dan flavonoid (Heyne, 1987). Skrining fitokimia yang telah dilakukan Sulistyaningsih dkk. (2009) menyatakan bahwa selain senyawa-senyawa tersebut, daun sukun juga mengandung senyawa steroid dan triterpenoid. Senyawa yang terkandung pada daun sukun memiliki banyak manfaat, diantaranya untuk penyakit liver, hepatitis, inflamasi, pembesaran limpa, jantung, ginjal, dan penyakit kulit (gatal-gatal, bengkak, borok, dan infeksi kulit lainnya) (Heyne, 1987).

Dengan banyaknya manfaat yang dimiliki daun sukun, maka dapat membuka peluang dalam penemuan obat-obat berkhasiat untuk berbagai penyakit. Oleh karena itu penelitian ini dilakukan untuk mengetahui karakterisasi dan metabolit sekunder yang diproduksi oleh isolat jamur endofit sebagai upaya pencarian alternatif baru dengan memanfaatkan jamur endofit untuk pengembangan bahan baku obat yang berasal dari alam.

\section{METODE PENELITIAN}

\section{Bahan}

Bahan yang digunakan dalam penelitian ini, meliputi metanol 70\%, $\mathrm{NaOCl} 5,25 \%$, medium PDA, medium PDB, antibiotik kloramfenikol $100 \mathrm{mcg} / \mathrm{mL}$, kertas Whatman no. 41, Plat KLT $\mathrm{GF}_{254}$, n-Heksan, Etil asetat, Kloroform, metanol murni, air suling, pereaksi $\mathrm{FeCl} 3$ 10\%, Sitroborat, Liberman-Burcard, $\mathrm{H}_{2} \mathrm{SO}_{4} 10 \%, \mathrm{HCl} 37 \%$.

\section{Peralatan}

Alat-alat yang digunakan dalam penelitian, meliputi autoklaf, cawan Petri, bisturi (skalpel), ose bulat, Erlenmayer, beaker glass, pembakar spiritus, tabung reaksi, mikrometer skrup, mikropipet, pipet ukur, labu takar, timbangan digital, Rotary shaker, Hot plate, LAF (Laminar Air Flow), lampu UV 366 nm dan UV 254 nm, oven, inkubator, sentrifuge, gelas ukur, chamber, penggaris dan cawan porselin. 


\section{Prosedur}

\section{Isolasi Jamur Endofit}

Proses isolasi jamur endofit dari daun sukun (Artocarpus altilis) dilakukan dengan metode sterilisasi permukaan (surface sterilization) bertingkat. Perlakuan awal dilakukan dengan membersihkan daun sukun menggunakan air mengalir. Daun yang telah dibersihkan, selanjutnya dilakukan sterilisasi permukaan dengan cara merendam daun ke dalam metanol 70\% selama 1 menit, kemudian direndam dengan $\mathrm{NaOCl} 5,25 \%$ selama 3 menit, dan dilanjutkan dengan perendaman kembali menggunakan metanol $70 \%$ selama 30 detik untuk membilas $\mathrm{NaOCl}$ yang masih terdapat pada permukaan daun. Daun selanjutnya dikeringkan dari sisa pelarut dengan menggunakan tissue steril. Daun yang telah disterilisasi permukaan, kemudian dibuka jaringan daun secara horizontal menggunakan pisau bisturí (skalpel) dengan ukuran $\pm 1 \times 1 \mathrm{~cm}$. Ditempelkan jaringan daun yang telah dipotong pada medium PDAC (Potato Dextrose Agar Cloramfenicol). Medium ini merupakan medium PDA yang mengandung kloramfenikol $100 \mu \mathrm{g} / \mathrm{mL}$. Medium yang telah ditempelkan jaringan daun sukun, selanjutnya diinkubasi selama 7-14 hari pada suhu ruang $\left(22^{\circ} \mathrm{C}-25^{\circ} \mathrm{C}\right)$. Pengamatan dilakukan setiap hari hingga tampak koloni jamur yang tumbuh.

Koloni jamur yang tumbuh disekitar jaringan daun sukun pada medium PDAC, kemudian dimurnikan (purifikasi) berdasarkan warna dan bentuk pertumbuhan koloni jamur. Pemurnian dilakukan berulang kali hingga diperoleh isolat jamur endofit. Proses pemurnian dilakukan dengan cara menginokulasi jamur endofit pada satu titik ditengah cawan petri. Selanjutnya diinkubasi selama 2 hingga 5 hari pada suhu ruang $\left(22^{\circ} \mathrm{C}-25^{\circ} \mathrm{C}\right)$. Jika hasil inkubasi terdapat perbedaan warna dan bentuk koloni jamur, maka diisolasi kembali ke media PDA yang baru. Diinkubasi hingga didapatkan isolat jamur endofit yang murni dengan melihat ciri-cirinya secara visual.

\section{Produksi Metabolit Sekunder Isolat Jamur Endofit}

Isolat jamur endofit yang telah dimurnikan diinokulasikan ke dalam $50 \mathrm{~mL}$ medium PDB dalam Erlenmeyer dan diinkubasi selama 3-5 hari pada suhu ruang $\left(22^{\circ} \mathrm{C}-25^{\circ} \mathrm{C}\right)$. Diambil volume sebanyak $20 \mathrm{~mL}$ dari hasil pembenihan, yang selanjutnya diinokulasi ke dalam medium PDB baru dengan volume yang lebih besar dalam Erlenmeyer $250 \mathrm{~mL}$ dan ditambahkan serbuk kaca atau pecahan kaca ke dalam Erlenmeyer tersebut. Kemudian diinkubasi menggunakan shaker selama 2 minggu pada suhu ruang $\left(22^{\circ} \mathrm{C}-25^{\circ} \mathrm{C}\right)$ dengan kecepatan $150 \mathrm{rpm}$ (kocokan/ menit). Hasil inkubasi yang berupa miselium jamur endofit dipisahkan dari medium PDB dengan cara disaring dengan kertas saring Whatmann no. 41. Miselium jamur endofit selanjutnya dikeringkan menggunakan oven pada suhu $40^{\circ} \mathrm{C}-$ $50^{\circ} \mathrm{C}$, setelah kering miselium diekstraksi dengan metode maserasi menggunakan metanol.

\section{Identifikasi Golongan Metabolit Sekunder}

Identifikasi golongan metabolit sekunder dilakukan dengan menggunakan metode análisis KLT (Kromaografi Lapis Tipis) dan uji tabung. Eluen yang digunakan perbandingan pelarut Heksan : Etil asetat dan Kloroform : Metanol yang dibuat dalam 1 $\mathrm{mL}$.

\section{Flavonoid.}

Identifikasi senyawa flavonoid dilakukan penyempotan dengan pereaksi sitroborat. Hasil positif jika terdapat bercak warna hijau kekuningan pada penyinaran dengan UV 366 nm. 


\section{Polifenol.}

Identifikasi senyawa polifenol dilakukan dengan menyemprotkan pereaksi $\mathrm{FeCl}_{3} 10 \%$. Hasil positif jika terdapat bercak noda berwarna biru kehitaman hingga hitam setelah plat kromatogram dipanaskan pada suhu $105^{\circ} \mathrm{C}$ selama 15 menit.

\section{Triterpen.}

Identifikasi senyawa triterpen dilakukan dengan pereaksi Liberman-Burchard. Hasil positif jika terdapat bercak noda berwarna merah hingga ungu setelah dipanaskan pada suhu $105^{\circ} \mathrm{C}$ selama 15 menit.

\section{Steroid.}

Identifikasi senyawa steroid dilakukan dengan pereaksi Liberman-Burchard. Hasil positif jika terdapat bercak noda warna hijau hingga biru pada penyinaran dengan UV 366 nm.

\section{Saponin.}

Identifikasi senyawa saponin dilakukan dengan uji tabung. Ekstrak isolat jamur endofit ditambahkan dengan air suling dan dikocok selama 30 detik. Jika terbentuk busa stabil selama 15 - 30 menit setelah penambahan $\mathrm{HCl}$ pekat dapat diindikasikan senyawa positif mengandung saponin.

\section{HASIL DAN PEMBAHASAN}

\section{Isolasi Jamur Endofit}

Berdasarkan hasil isolasi jamur endofit yang telah dilakukan pemurnian (purifikasi), diperoleh 2 isolat jamur endofit yang masing-masing isolat diberi kode $\operatorname{IFE}_{1} \mathrm{P}$ (berwarna putih) dan $\mathrm{IFE}_{2} \mathrm{HK}$ (berwarna hijau kehitaman). Isolat jamur endofit yang telah dipurifikasi selanjutnya dikarakterisasi. Karakterisasi ini bertujuan untuk mengetahui morfologi isolat jamur endofit melalui pengamatan secara makroskopis dan mikroskopis.

Hasil pengamatan isolat jamur endofit $\mathrm{IFE}_{1} \mathrm{P}$ secara makroskopis, menunjukkan koloni jamur endofit memiliki warna putih dengan tekstur granular atau granulose, dan sebalik koloni juga berwarna putih. Koloni jamur tampak dari atas permukaan berbentuk konsentrik dengan elevasi halus, dan bentuk penonjolan pada koloni jamur endofit timbul. Sedangkan pada pengamatan isolat jamur endofit $\mathrm{IFE}_{2} \mathrm{HK}$ secara makroskopis, menunjukkan koloni jamur endofit berwarna hijau kehitaman yang lambat laun berwarna abu-abu dengan tepi koloni berwarna hijau lumut dan memiliki tekstur velvety atau menyerupai beludru. Sedangkan sebalik koloninya berwarna hijau kehitaman dengan permukaan dari atas berbentuk bulat dengan tepi bergelombang. Elevasi koloni jamur endofit halus dengan penonjolan berbentuk bukit.

Hasil pengamatan isolat jamur endofit $\mathrm{IFE}_{1} \mathrm{P}$ secara mikroskopis menunjukkan pada pembesaran 400x, koloni jamur memiliki hifa aseptat dengan pigmentasi hialin (tak berwarna). Pada pembesaran 1000x tampak spora aseksual dari isolat jamur endofit berupa konidia. Konidia memiliki bentuk bulat dan klaster (berkelompok), yang dibentuk pada hifa khusus berupa konidiofor. Isolat jamur endofit $\mathrm{IFE}_{1} \mathrm{P}$ berada pada fase anamorf, karena hanya fase aseksualnya yang diketahui. Sedangkan pengamatan isolat jamur endofit $\mathrm{IFE}_{2} \mathrm{HK}$ secara mikroskopis, menunjukan pada pembesaran 400x terdapat hifa berseptat (berseptum) dan berpigmentasi hialin (tak berwarna). Hifa yang dimiliki isolat jamur endofit $\mathrm{IFE}_{2} \mathrm{HK}$ berbentuk rhizoid. Pada pembesaran $1000 \mathrm{x}$, isolat jamur endofit $\mathrm{IFE}_{2} \mathrm{HK}$ berada pada fase aseksualnya, karena terdapat konidiospora yang terbentuk pada sisi-sisi dan ujung hifa dengan bentuk semibulat bergerombol. 

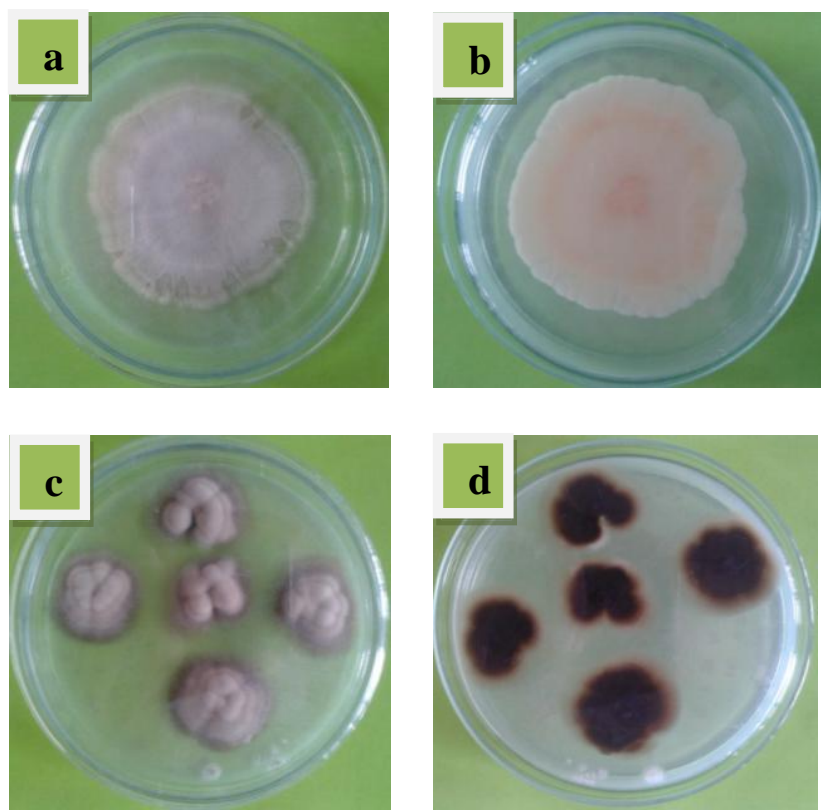

Gambar 1. Hasil Isolasi Jamur Endofit (a) Isolat Jamur Endofit IFE1P (b) Sebalik koloni $\mathrm{IFE}_{1} \mathrm{P}(\mathrm{c})$ Isolat Jamur Endofit $\mathrm{IFE}_{2} \mathrm{HK}$ dan (d) Sebalik Koloni $\mathrm{IFE}_{2} \mathrm{HK}$.
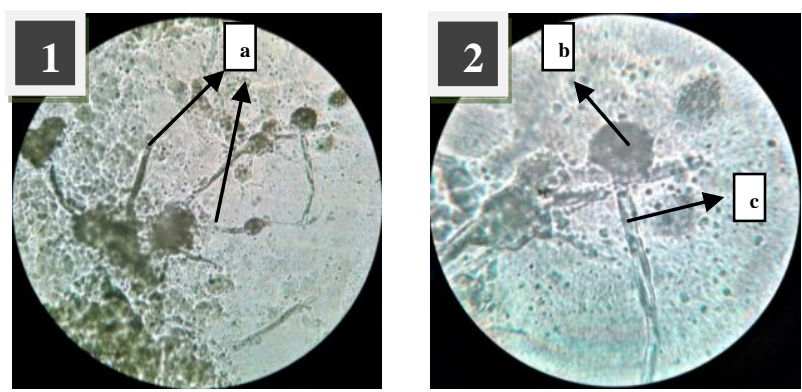

Gambar 2. Pengamatan Mikroskopik Isolat Jamur Endofit IFE1P dengan Pembesaran (1) 400x dan (2) 1000x. Bagian (a) Hifa, (b) Konidia dan (c) Konidiofor
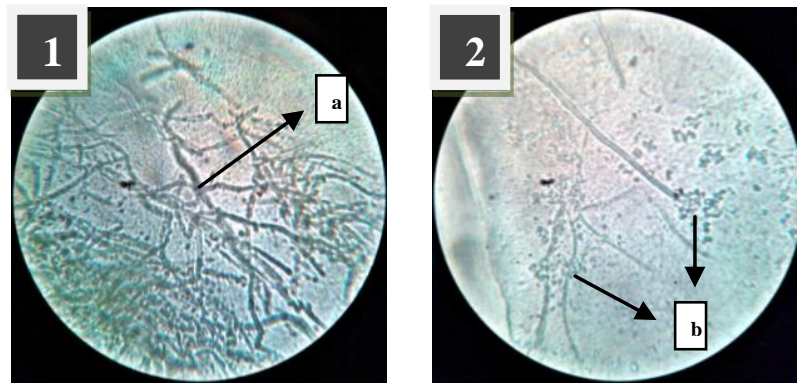

Gambar 3. Pengamatan Mikroskopik Isolat Jamur Endofit IFE2HK dengan Pembesaran (1) 400x dan (2) 1000x. Bagian (a) Hifa dan (b) Konidiospora. 


\section{Identifikasi Golongan Metabolit Sekunder}

Identifikasi metabolit sekunder yang dilakukan dalam pengujian ini, untuk mengetahui metabolit sekunder apa saja yang terdapat pada isolat jamur endofit $\operatorname{IFE}_{1} \mathrm{P}$ dan $\operatorname{IFE}_{2} \mathrm{HK}$. Eluen yang digunakan sebagai fase gerak berupa perbandingan pelarut n-Heksan : Etil asetat (7:3) untuk mengelusi ekstrak metanol isolat $\operatorname{IFE}_{1} \mathrm{P}$, sedangkan ekstrak metanol isolat $\mathrm{IFE}_{2} \mathrm{HK}$ menggunakan perbandingan pelarut Kloroform : Metanol (9:1). Menurut Carlile (2001), metabolisme sekunder pada jamur endofit secara umum terjadi pada saat fase pertumbuhan yang akan segera berakhir dan mulai memasuki fase stasionernya. Hal tersebut mendukung pernyataan Gandjar dkk. (2006), yang menyatakan bahwa metabolit sekunder dari jamur endofit dapat dipanen pada fase stasioner dari pertumbuhan jamur endofit. Fase stasioner dapat terjadi ketika, antara jumlah sel yang membelah dengan jumlah sel yang mengalami kematian dalam keadaan seimbang.

Berdasarkan hasil identifikasi golongan metabolit sekunder dari ekstrak metanol isolat jamur endofit $\mathrm{IFE}_{1} \mathrm{P}$ dan $\mathrm{IFE}_{2} \mathrm{HK}$ yang telah dilakukan, dapat dilihat pada Tabel 1.

Tabel 1. Identifikasi Gologan Metabolit Sekunder

\begin{tabular}{|c|c|c|c|c|c|c|}
\hline \multirow{2}{*}{$\begin{array}{l}\text { Metabolit } \\
\text { Sekunder }\end{array}$} & \multirow{2}{*}{$\begin{array}{l}\text { Pereaksi } \\
\text { Semprot/ } \\
\text { Tetes }\end{array}$} & \multirow{2}{*}{$\begin{array}{l}\text { Hasil } \\
\mathrm{IFE}_{1} \mathrm{P}\end{array}$} & \multicolumn{3}{|c|}{ Nilai Rf } & \multirow[b]{2}{*}{ Reaksi Positif } \\
\hline & & & $\mathrm{IFE}_{\mathbf{2}} \mathrm{HK}$ & $\mathrm{IFE}_{1} \mathbf{P}$ & $\mathrm{IFE}_{2} \mathrm{HK}$ & \\
\hline Flavonoid & Sitroborat & + & + & $\begin{array}{l}0,64 \\
0,84 \\
0,91 \\
\end{array}$ & $\begin{array}{l}0,54 \\
0,64\end{array}$ & $\begin{array}{c}\text { Bercak noda hijau } \\
\text { kekuningan UV } \\
366 \\
\end{array}$ \\
\hline Polifenol & $\mathrm{FeCl}_{3} 10 \%$ & + & + & $\begin{array}{l}0,84 \\
0,91 \\
\end{array}$ & 0,73 & Bercak noda hitam \\
\hline Triterpenoid & $\begin{array}{l}\text { Liberman- } \\
\text { Burchard }\end{array}$ & + & + & 0,23 & $\begin{array}{l}0,22 \\
0,34\end{array}$ & $\begin{array}{c}\text { Bercak noda } \\
\text { berwarna merah } \\
\text { hingga ungu }\end{array}$ \\
\hline Steroid & $\begin{array}{l}\text { Liberman- } \\
\text { Burchard }\end{array}$ & + & + & $\begin{array}{l}0,23 \\
0,48 \\
0,72 \\
0,91 \\
\end{array}$ & $\begin{array}{l}0,22 \\
0,43 \\
0,64\end{array}$ & $\begin{array}{c}\text { Bercak noda hijau } \\
\text { hingga biru UV } \\
366\end{array}$ \\
\hline Saponin & $\mathrm{HCl}$ Pekat & + & - & - & - & $\begin{array}{c}\text { Busa stabil } 15-30 \\
\text { menit }\end{array}$ \\
\hline
\end{tabular}

Hasil identifikasi menunjukkan bahwa isolat jamur endofit $\operatorname{IFE}_{1} \mathrm{P}$ dan $\operatorname{IFE}_{2} \mathrm{HK}$ memiliki metabolit sekunder berupa flavonoid, polifenol, triterpenoid dan steroid. Sedangkan metabolit sekunder saponin hanya teridentifikasi pada isolat $\mathrm{IFE}_{1} \mathrm{P}$ dan tidak teridentifikasi pada isolat $\mathrm{IFE}_{2} \mathrm{HK}$. Senyawa saponin yang tidak teridentifikasi tersebut, dimungkinkan karena selama proses penyarian secara maserasi senyawa tidak terekstraksi dengan sempurna. Selain itu dapat disebabkan karena konsentrasi senyawa saponin yang terekstraksi sangat rendah, sehingga ketika dilakukan identifikasi pada ekstrak metanol isolat jamur endofit $\mathrm{IFE}_{2} \mathrm{HK}$ senyawa tidak teridentifikasi. Petrini dkk. (1992), menyatakan bahwa untuk memproduksi metabolit sekunder dari jamur endofit diperlukan medium yang ideal dengan kondisi optimal yang sesuai. Terdapat beberapa faktor substrat yang berpengaruh terhadap mekanisme biosíntesis jamur endofit dalam memproduksi metabolit sekunder, seperti sumber Karbon (C), Nitrogen (N) dan beberapa vitamin yang diperlukan dalam biosíntesis jamur endofit. Diduga faktor-faktor tersebut yang menyebabkan produksi metabolit sekunder tidak maksimal. 


\section{KESIMPULAN}

1. Diperoleh 2 isolat jamur endofit dari daun sukun (Artocarpus altilis) yang masingmasing isolat diberi kode $\operatorname{IFE}_{1} \mathrm{P}$ (berwarna putih) dan $\mathrm{IFE}_{2} \mathrm{HK}$ (berwarna hijau kehitaman).

2. Karakterisasi secara makroskopis pada isolat $\mathrm{IFE}_{1} \mathrm{P}$, koloni berwarna putih dengan tekstur granular, permukaan konsentris dengan elevasi halus dan penonjolan timbul. Secara mikroskopis terdapat hifa aseptat, konidia dan konidiofor. Isolat $\mathrm{IFE}_{2} \mathrm{HK}$ secara makroskopis, koloni berwarna hijau kehitaman dengan tekstur beludru, berbentuk bulat dengan tepi bergelombang dan elevasi halus dengan penonjolan berbentuk bukit. Secara mikroskopis terdapat hifa septat berbentuk rhizoid dan konidiospora.

3. Golongan senyawa metabolit sekunder yang dihasilkan oleh isolat $\operatorname{IFE}_{1} \mathrm{P}$ dan $\mathrm{IFE}_{2} \mathrm{HK}$ adalah flavonoid, polifenol, steroid dan triterpenoid. Untuk senyawa saponin hanya terdapat pada isolat $\mathrm{IFE}_{1} \mathrm{P}$ dan tidak teridentifikasi pada isolat $\mathrm{IFE}_{2} \mathrm{HK}$.

\section{SARAN}

Diperlukan kajian penelitian dan penelitian lanjutan untuk tingkatan fraksinasi hingga isolasi senyawa. Serta upaya dalam pegujian aktivitas dan pengembangan formulasi sediaan yang berasal dari senyawa aktif yang dihasilkan oleh jamur endofit daun sukun.

\section{DAFTAR PUSTAKA}

Carlile, M.J., S.C. Watkinson, dan G.W. Gooday. 2001. The fungi. Academic Press; California.

Gandjar, I., W. Sjamsuridzal, dan A. Oetari. 2006. Mikologi dasar dan terapan. Yayasan Obor Indonesia; Jakarta.

Heyne, K. 1987. Tumbuhan Berguna Indonesia III Edisi ke-1. Penerbit Yayasan Sarana Wana Jaya; Jakarta.

Petrini OTN, Sieber LT, Viret O. 1992. Ecology Metabolite Production and Substrate Utilization In Endophytic Fungi. Nat Toxin. 1: 189-196.

Radji, M. 2005. Buku Ajar Mikrobiologi Panduan Mahasiswa Farmasi dan Kedokteran. EGC; Jakarta.

Strobel GA., and B. Daisy. 2003. Bioprospecting for Microbial Endophytes and Their Natural Products. Microbiol. and Mol. Biology Rev. 67(4): 491-502.

Strobel GA. 2004. Natural Products from Endophytic Microorganism. Journal of Natural Products. 67: 257-268.

Sulistyaningsih, Rostinawati T, dan Permana C. 2009. Aktivitas Antimikroba Ekstrak Etanol Daun Sukun (Artocarpus altilis [Parkins.] Fosbberg Terhadap Bakteri Eschericia coli, Bacillus subtilis, dan Jamur Candida albicans, Microsporum gypsium. Farmaka. 7 (1): 1-14.

Tan, RX and WX Zou. 2001. Endophytes: a Rich Source of Functional Metabolites. Nat Prod.Rep. 18: 448-459.

Tombe, M. 2008. Fungi Endofit Sebagai Penghasil Antibiotika. C.V. Meori Agro; Jakarta. 